\title{
Variable Expressivity in Fragile X Syndrome: Towards the Identification of Molecular Characteristics That Modify the Phenotype
}

\author{
César Payán-Gómez $\mathbb{I D}^{\prime}$ \\ Julian Ramirez-Cheyne 2,3 \\ Wilmar Saldarriaga ${ }^{2,3}$ \\ 'Deparment of Biology, Faculty of \\ Natural Sciences, Universidad del \\ Rosario, Bogotá, Colombia; ${ }^{2} \mathrm{Health}$ \\ Faculty, Universidad del Valle, Cali, \\ Colombia; ${ }^{3}$ Hospital Universitario del \\ Valle, Cali, Colombia
}

\begin{abstract}
Fragile X syndrome (FXS), is an X-linked inherited genetic disease. FXS is the leading cause of inherited intellectual disability and autism in the world. Those affected are characterized by intellectual disability, language deficit, typical facies, and macroorchidism. Alterations in the FMR1 gene have been associated with FXS. The majority of people with this condition have an allele with an expansion of more than 200 repeats in a tract of CGGs within the $5^{\prime}$ untranslated region, and this expansion is associated with a hypermethylated state of the gene promoter. FXS has incomplete penetrance and variable expressivity. Intellectual disability is present in $100 \%$ of males and $60 \%$ of females. Autism spectrum disorder symptoms appear in $50 \%$ to $60 \%$ of males and $20 \%$ of females. Other characteristics such as behavioral and physical alterations have significant variations in presentation frequency. The molecular causes of the variable phenotype in FXS patients are becoming clear: these causes are related to the FMRI gene itself and to secondary, modifying gene effects. In FXS patients, size and methylation mosaicisms are common. Secondary to mosaicism, there is a variation in the quantity of FMRI mRNA and the protein coded by the gene Fragile Mental Retardation Protein (FMRP). Potential modifier genes have also been proposed, with conflicting results. Characterizing patients according to CGG expansion, methylation status, concentration of mRNA and FMRP, and genotypification for possible modifier genes in a clinical setting offers an opportunity to identify predictors for treatment response evaluation. When intervention strategies become available to modulate the course of the disease they could be crucial for selecting patients and identifying the best therapeutic intervention. The purpose of this review is to present the information available about the molecular causes of the variability of the expression incomplete penetrance and variable expressivity in FXS and their potential clinical applications.
\end{abstract}

Keywords: FMR1, FMRP, methylation, mosaicisms, modifier, genes

\section{Introduction}

Fragile X syndrome (FXS), OMIM \# 300624, is a X-linked inherited genetic disease classified as a triplet repeat condition. FXS is the most common cause of inherited intellectual disability and autism in the world. It has a prevalence of 1 in 5000 men and 1 in 8000 women. Affected individuals are characterized by intellectual disability, autism, language deficit, typical facies, and macroorchidism. ${ }^{1,2}$

Alterations in the FMR1 gene with locus Xq27.3 are causative of Fragile $\mathrm{X}$ Syndrome and other disorders. This gene harbors a CGG repeat within the 5' untranslated region and, depending on the number of repetitions, 4 types of alleles
Correspondence: Wilmar Saldarriaga, Health Faculty, Universidad del Valle, Calle 4b \#36 00, Building 116 Office 29, Cali, Colombia

$\mathrm{Tel} / \mathrm{Fax}+573182800698$

Email wilmar.saldarriaga@correounivalle. edu.co 
are defined with different clinical manifestations: ${ }^{3}$ Normal alleles, which have up to 44 CGG repeats; grey zone or intermediate alleles that contain between 45 and 54 repeats; premutation (PM) alleles with between 55 and 200 repeats; and full mutation (FM) alleles, with more than 200 repeats. In most cases, this is due to an expansion of the CGG triplet from one generation to the next. ${ }^{4}$

The Fragile Mental Retardation Protein (FMRP) is coded by the FMR1 gene. The absence of FMRP expression is usually secondary to the methylation of the FMRI gene that occurs when more than 200 CGG repeats are present in the $5^{\prime} \mathrm{UTR}$ region; this can also be explained by a point mutation in the coding region for FMRI or a deletion that includes this gene, but these changes have only been reported in a few cases. The absence of FMRP is related to the classic FXS phenotype. ${ }^{5,6}$

FMRP expression is slightly lower in the carriers of a PM allele. Lower levels of FMRP are found particularly in the upper premutation (PM) range however, they typically do not present the classic FXS syndrome phenotype. ${ }^{7}$ Furthermore, they have elevated FMRI mRNA levels between 2 to 8 times normal levels, which also leads to RNA toxicity. These elevated levels of mRNA are a risk for a number of medical conditions that are not explained by decreased FMRP., ${ }^{2,4}$

FMRP has roles in chromatin dynamics, RNA binding, mRNA transport, and mRNA translation ${ }^{9,10}$ and for certain subgroups of cerebral transcripts. ${ }^{11}$

This protein is involved in the regulation of RNA stability, subcellular transport and translation of neural mRNAs that codify proteins involved in synapsis development, neural plasticity and brain development. ${ }^{8}$

In addition, FMRP interacts with at least 180 proteins expressed in the brain and connective tissue. This interactome comprises known FMRP-binding proteins, including the ribosomal proteins FXR1P, NUFIP2, Caprin-1, and other novel FMRP-interacting candidate proteins located in different subcellular compartments, including CARF, LARP1, LEO1, NOG2, G3BP1, NONO, NPM1, SKIP, SND1, SQSTM1 and TRIM28. This interactome suggests that, besides its known functions, FMRP is involved in transcription, RNA metabolism, ribonucleoprotein stress granule formation, translation, DNA damage response, chromatin dynamics, cell cycle regulation, ribosome biogenesis, miRNA biogenesis and mitochondrial organization. $^{9}$

Several studies have shown that in the absence of FMRP, a wide range of neural mRNAs are affected, boosting neural protein synthesis, which results in dendritic spine dysmorphogenesis and glutamate/GABA imbalance, which in turn produce variations in neural excitation/ inhibition, phenomena that are present in FXS. Dendritic spine dysmorphogenesis plays a role in the intellectual deficits and behavioral problems, due to the weak synaptic connections found in this syndrome. ${ }^{12,13}$

Fragile X syndrome (FXS) has incomplete penetrance and variable expressivity and biological sex is a decisive factor of the phenotype. Full mutation of the FMR1 gene has a $100 \%$ penetrance of intellectual disability in males and $60 \%$ in females. Other characteristics associated with FXS Appear with varying frequencies in affected individuals. Autism spectrum disorder (ASD) symptoms appear during early childhood in $50 \%$ to $60 \%$ of males and $20 \%$ of females with FXS. ${ }^{14-17}$

Physical features include elongated face, large and prominent ears (75-78\% of affected males), mandibular prognathism ( $80 \%$ of adult men), hyperlaxity and macroorchidism ( $95 \%$ of adult men). Other characteristics also vary in their frequency of presentation: seizures (23\%), strabismus (8\%), and cardiac abnormalities such as abnormal aortic root dimensions (18\%) and mitral valve prolapse $(55 \%)$. In general, the female phenotype is less severe and less specific. ${ }^{4,18}$

The variation in the phenotype of monogenic diseases is common, ${ }^{19,20}$ it is explained by a combination of genetic, environmental, and lifestyle factors, ${ }^{21}$ and FXS is not an exception.

Here, we present a review of the knowledge about the molecular factors involved in the variable expressivity of FXS.

\section{First Level of Categorization in FXS Patients, The Monogenic View: Alteration of FMRI Function}

The presence of a full mutation in FMRl is associated with the hypermethylation of a $\mathrm{CpG}$ island located in the promoter of the FMR1 gene. Methylation of DNA regions (mDNA) is one of the main epigenetic modifications related to transcription regulation. ${ }^{22} \mathrm{~A} \mathrm{CpG}$ island is located proximal to the CGG repeat tract, which is expanded in FXS. Hypermethylation of the $\mathrm{CpG}$ island generates transcriptional silencing of the FMRl gene. ${ }^{23}$ As a consequence, the Fragile Mental Retardation Protein (FMRP), codified by the FMRI gene, is not produced ${ }^{24}$ and in turn, the absence or low expression of FMRP causes FXS. 
CGG tract repetition expansion in the untranslated region (UTR) of exon 1 in the FMRl gene generates instability of that region during the replication process, inducing size mosaicism, which is defined as the presence of premutation and mutation alleles in several cells. ${ }^{25}$

In males with FXS caused by full mutation, the detection of FMR1 mRNA levels in peripheral blood lymphocytes is common. This phenomenon is due to both size mosaicism and mDNA in the $\mathrm{CpG}$ island and nearby regions that vary between cells and tissues. ${ }^{26}$ Furthermore, longitudinal studies in women with FXS have shown that levels of mRNA transcribed from FMRI decrease significantly with age. ${ }^{23}$ Complicating even more the behavior of mDNA and FXS, it has been found that in premutation alleles, a considerable number of cells have mDNA. ${ }^{27}$ The variation between methylation states of the $\mathrm{CpG}$ island and nearby regions among different cells and tissue of the same person is known as methylation mosaicism. ${ }^{28}$ It is estimated that around $50 \%$ of people with FXS have this type of mosaicism. ${ }^{29}$ In cells where mutated alleles are not methylated, they are transcriptionally active and can be expressed. ${ }^{30}$ However, in these cells there is no FMRP synthesis since mRNA with CGG expansion greater than 200 repeats is not translated efficiently in ribosomes. ${ }^{31,32}$

\section{FMRP Expression}

The absence or low levels of FMRP is a decisive factor for FXS development, as several studies have aimed to discover the relationship between protein levels and phenotypic characteristics of the patients. Since the late 1990s, correlations between FMRP levels and the neurological phenotype of FXS have been established. ${ }^{29,33,34}$ The first studies about this topic established the standard levels of FMRP in peripheral blood leucocytes through immunoblotting. When comparing protein levels with the allele type and the presence of size mosaicism, it was demonstrated that people with the lowest FMRP levels were males with FM. Males with size mosaicism and females with FM had slightly higher levels of FMRP than males with FM. ${ }^{33,35,36}$ Via multiple regression models, it was found that FMRP levels were significantly correlated with the intelligence quotient (IQ) of the patients in the study ${ }^{33}$ However, studies did not identify the same relation between FMRP levels and behavioral symptoms. ${ }^{34,37}$ More recent evidence supports a partial overlap between the pathogenic mechanisms that lead to FXS and ASD. ${ }^{38}$ Lower FMRP levels have been documented in samples of individuals with FXS and ASD compared to patients with FXS only. ${ }^{29,34}$ The relation between FMRP levels and IQ in males and females with different expansions in CGG repeats was studied recently. ${ }^{39}$ This last study has two important advantages compared with previous studies: firstly, the use of fluorescence resonance energy transfer (FRET), which has a higher sensibility when measuring protein levels, and also FMRP levels were measured in dermal fibroblasts. Unlike leucocytes, fibroblasts derive from the ectoderm, the same germ layer from which nervous system cells originate. Researchers found a strong and positive relation between FMRP levels and cognitive skills in patients with levels below $30 \%$ of the standard levels in controls. Interestingly, above this level, there was a higher dependence between low FMRP levels and low IQ. ${ }^{39}$

\section{Size and Methylation Mosaicisms}

In parallel with the aforementioned studies, researchers reported the incidence of size and methylation mosaicism in cognitive impairment severity. ${ }^{40-42}$ The classic definition of premutation alleles' behavior as non-methylated alleles, and mutated alleles as methylated or partially methylated ones in order to categorize premutation carriers and patients with FXS has been extended progressively to include a detailed classification that takes into account the existence of size and methylation mosaicisms.

Regarding size mosaicisms, different combinations have been described, including patients with some FM cells and other cells with PM. Indeed, patients with FM, PM, grey zone alleles and even alleles with normal size have been reported. ${ }^{40}$ The presence of size mosaicisms with PM and FM alleles is related with a less severe phenotype and a higher risk of developing fragile $\mathrm{X}$-associated tremor/ataxia syndrome (FXTAS). ${ }^{43}$

When exploring the possible relation between size mosaicisms and the intellectual functioning of patients with FXS disregarding sex, it was found that patients with FM/PM had better intellectual functioning and less maladaptive behavior, compared with FM-affected individuals. ${ }^{42}$ Interestingly, the same study found that ASD features and maladaptive behaviors were similar between FM-only and PM/FM mosaics within each sex, after controlling for overall intellectual functioning. A limitation of this study is that they used venous blood and real time PCR and Southern blot analysis to quantify the level of methylation. 
Recently, methylation mosaicism has been taken into account as an important variable in phenotype traits. The most frequent mosaicism found in males is the presence of FM-methylated alleles and non-methylated FM and PM alleles (combination of size and methylation mosaicism) ${ }^{25,44}$ However, in patients with FM and not PM mosaicisms, methylated alleles do not express mRNA, while non-methylated alleles do. An aspect that highlights the importance of detecting the presence of this kind of mosaicism is the influence on phenotype severity. Additionally, according to some case reports, the presence of synthesized mRNA from PM and FM alleles increases the odds of developing the FXTAS phenotype. ${ }^{45,46}$ The final consequence of methylation mosaicism is the cell's reduced ability to express FMR1 mRNA, measure mRNA and determine if there is a relation with phenotypic traits. When analyzing mRNA levels between males and females, it was found that females had higher levels. Also, in females, higher levels of FMR1 mRNA were related positively with age but not with intellectual functioning and autistic features. Males with FM that express FMR1 mRNA had significantly higher ADOS calibrated severity scores, when compared with males with fully methylated FM. Interestingly, no differences were found regarding intellectual functioning. ${ }^{41}$ Likewise, when contrasting FMR1 mRNA levels and scores on the Aberrant Behavior Checklist-Community-FXS version (ABC-CfX) it was found that in males with FM, higher values of FMR1 mRNA were related with elevated irritability and lower health-related quality of life scores. ${ }^{47}$ This association was not found in males with $\mathrm{PM} / \mathrm{FM}$, suggesting that for improved genotype/phenotype associations, it is essential to take into consideration not only sex but also size and methylation mosaicism.

Recent investigations explored simultaneously how FMR1 mRNA levels of FMRP are related to phenotypic alterations in males with PM and FM. ${ }^{48}$ In a study composed of 14 cases of patients with PM or PM and FM mosaicism and mental illnesses such as bipolar disorder, schizophrenia and psychosis, among others, low levels of FMRP and increased FMR1 mRNA were evident in these patients. This combination of characteristics in patients with FM, decreased FMRP, PM and increased FMR1 mRNA represents a dual mechanism of clinical significance that may generate characteristics of both FXS and FXTAS. ${ }^{48}$ In a clinic-based ascertained group of patients with FXS of both gender, a significant difference was found between FXS with ASD and low levels of FMRP when comparing concentrations of the protein in patients with FXS without ASD. ${ }^{29}$ They found that the mean full scale IQ and adaptive skills composite scores were significantly lower in males than in females $(\mathrm{p}=0.016$ and $\mathrm{p}=$ 0.001, respectively, Mann-Whitney). Additionally, all individuals with moderate or severe ID were males. Not surprisingly, ASD was present more frequently in males with FXS (46\% vs $20 \%$ females). This association was not found in males with PM/FM, suggesting that for improved genotype/phenotype associations is essential to take into consideration not only sex but size and methylation mosaicism. ${ }^{29}$

\section{Other FMRI Mutations}

There is a small proportion of FXS patients without expansions in the CGG-repeat tract. In this group, the condition is caused by missense or nonsense mutations, ${ }^{5,16}$ or deletions in FMR 1. ${ }^{1,6}$ Patients with these mutations have similar physical, cognitive and behavioral characteristics to FXS patients. With the increasing availability of diagnostic methods based on next-generation sequencing and comparative genomic hybridization, a higher rate of diagnosis of mutations causing FMR1 function loss is expected. This will allow a clear delimitation of the phenotype caused by the loss of the protein in the absence of CGG tract expansions.

\section{Second Level of Categorization in FXS Patients: Search for Modifier Genes Affecting the Genotype}

For many monogenic diseases it is known that, besides the allelic variance, the effect of modifier genes has an important role in incomplete penetrance and variable expressivity. The identification of modifier genes that affect the phenotype in monogenic diseases has many challenges that complicate their description. A genetic variant can modify the effect in the phenotype of another variant in many ways, including epistasis and genetic interactions. $^{49,50}$

In studies using FXS murine models, important new evidence was acquired in order to establish the importance of potential modifier genes and their impact on FXS phenotype development. The knockout mouse model for FXS was generated in the last decade of the XX century. Fmr1 KO mice had learning deficits, abnormal synaptic connections, seizures, hyperactivity and macroorchidism. ${ }^{51,52}$ When describing the mouse phenotype in detail, it was 
evident that abnormal phenotypic characteristics depend, at least in some proportion, on their genetic background. ${ }^{53}$

During the identification of modifier genes in the FXS phenotype, a large proportion of the research has aimed towards the susceptibility to developing certain clinical behavioral characteristics, such as aggression, ASD and seizures. ${ }^{34,54-59}$ All of the studies use a similar methodological design: they arrange groups of people with or without a specific phenotypic trait and establish the frequency of specific variants in modifier gene candidates.

The possibility that Val66Met polymorphism in the brain-derived neurotrophic factor (BDNF) gene may modulate the epilepsy phenotype in FXS patients has also been investigated. The replacement of a methionine for a valine in the $66^{\text {th }}$ position of the BDNF protein interferes with normal intracellular traffic and BDNF dependent secretory activity in cortical neurons. ${ }^{60}$ This polymorphism has been related to cerebral anatomy alterations ${ }^{61}$ and neuropsychiatric disorders. ${ }^{62,63}$ In a sample of 27 males with FXS from Finland, it was found that all the patients with epilepsy (15\%) had the Met66 allele, whereas the prevalence of this allele is $20 \%$ in the normal population. Research suggests that the Met66 allele in BDNF interacting with FM in FMR1 may partially explain the higher incidence of seizures in patients with FXS. ${ }^{56}$ In a more recent study with a higher number of males with FXS (77 patients), the results were not replicated and there was no association between seizures and Val66Met polymorphism. ${ }^{58}$ These results show the importance of validating studies about modifier genes in different populations.

In research about genes that affect mood and aggression, such as the serotonin transporter (5-HTTLPR), the monoamine oxidase A (MAOA-VNTR) and COMT, conflicting results were found. All of those genes are involved in regulatory pathways for different neurotransmitters, and their variants have been associated with the development of behavioral phenotypes in different contexts other than FXS. In one group of 50 males with FXS, the relationship of 5-HTTLPR and MAOA-VNTR polymorphisms with the frequency/severity of aggressive/destructive, selfinjurious and stereotypic behaviors was studied. It was found that the high-transcribing long $(\mathrm{L} / \mathrm{L})$ genotype in 5-HTTLPR was related with a higher frequency of aggressive/destructive and stereotypic behavior, while patients with the short $(\mathrm{S} / \mathrm{S})$ genotype had less aggression. The MAOA-VNTR genotype had no effect on behavior. ${ }^{55}$ On the other hand, in a study of 64 males with FXS where the COMT gene was also included, the results of the previous study were not replicated. There was no association between behavioral characteristics and either 5-HTTL PR (serotonin) or MAOA genotypes. Nevertheless, the A/A genotype in COMT that modifies dopamine levels was associated with greater interest and pleasure in the environment, and with less risk of property destruction, stereotyped behavior and compulsive behavior. ${ }^{54}$ The authors of the study suggest that the non-reproducibility of the results regarding MAOA-VNTR can be explained by differences in the prevalence of aggressive and stereotyped behavior among the studied populations or by differences in the measurements used to characterize each behavior.

The importance of identifying potential modifier genes was explored in a clinical trial. The researchers investigated the relation between polymorphisms in several genes and the response of sertraline in 51 children. They found that BDNF, MAOA, 5-HTTLPR, Cytochrome P450 2C19 and 2D6 polymorphisms had significant correlations with treatment response. ${ }^{64}$

\section{Summary of the Knowledge of the Molecular Causes Regarding the Variable Phenotype in FXS}

Currently the knowledge about molecular causes of the variable phenotype in patients with FXS include characteristics associated with the FMRI gene itself and to secondary, modifying gene effects.

Regarding FMRl, when the diagnosis is established, the type of mutation causing FXS is identified: CGG repeat tract expansion vs pathological variant causing loss of function in FMRI.

When the CGG is identified, is it expected that about half of the patients have size or methylation mosaicism or both. $^{29}$ The presence of any of those mosaicisms determines the expression or not of FMR1 mRNA and FMRP. The quantity of FMRP is directly related with IQ. ${ }^{34,37,39}$ While the presence of size mosaicism is related with better intellectual functioning and less maladaptive behavior, ${ }^{29,42}$ elevated concentrations of FMR1 mRNA in patients with FM have been associated with a higher risk of developing FXTAS $^{45,46,48}$ and with the severity of behavioral symptoms. $^{47}$

The search for modifier genes affecting the phenotype has been carried out using the candidate genes strategy. Because high impact clinical manifestations in FXS are related with neurologic phenotypes, the studied candidate genes are involved in CNS development and the 
appearance of seizures (BNDF) $)^{56,60-62}$ and associated with mood and aggression (5-HTTLPR, MAOA-VNTR y COMT). ${ }^{54,55}$ Recent research has been done with small groups of patients and there are no conclusive results about the importance of these variants in modifier genes.

\section{Conclusion}

Scientific and clinical evidence about molecular causes of variable expressivity in FXS is growing quickly. It is evident that aspects of the mutation type in FMRI and the behavior of the CGG repeat tract are relevant in the presentation of the condition. Research about modifier genes is still emerging. There are important limitations such as sample size and comparability of different studies, mainly due to smaller groups of selected patients and the use of different tools for measuring the phenotypes.

Independent cohorts of patients with FXS across different continents have shown evidence that mosaicism, FMR1 mRNA or FMRP quantification are associated with the severity of the phenotype. However, this information cannot currently be used effectively in the integral management of patients. When intervention strategies become available in order to prevent the development of FXTAS, or when certain molecules can regulate levels of FMRP expression to measure FMR1 mRNA and FMRP, they could be crucial for selecting patients and identifying the best therapeutic intervention.

In clinical trials there is an important window of opportunity. Identifying mosaicism, measuring transcription/ translation activity of FMRl and stratifying patients by modifier genotypes ${ }^{29,65}$ will permit the identification of subgroups of patients with greater potential to respond to specific treatments.

\section{Disclosure}

The authors report no conflicts of interest in this work.

\section{References}

1. Coffee B, Keith K, Albizua I, et al. Incidence of Fragile X syndrome by newborn screening for methylated FMR1 DNA. Am J Hum Genet. 2009;85(4):503-514. doi:10.1016/j.ajhg.2009.09.007

2. Saldarriaga W, Tassone F, González-Teshima LY, Forero-Forero JV, Ayala-Zapata S. Fragile X Syndrome. Colomb Med. 2014;190-198. doi: $10.25100 / \mathrm{cm} . v 45 i 4.1810$

3. Bagni C, Tassone F, Neri G, Fragile HR. X syndrome: causes, diagnosis, mechanisms, and therapeutics. J Clin Invest. 2012;122 (12):4314-4322. doi:10.1172/JCI63141

4. Salcedo-Arellano MJ, Dufour B, McLennan Y, Martinez-Cerdeno V, Hagerman R. Fragile X syndrome and associated disorders: clinical aspects and pathology. Neurobiol Dis. 2020;136:104740. doi:10.1016/ j.nbd.2020.104740
5. Sitzmann AF, Hagelstrom RT, Tassone F, Hagerman RJ, Butler MG. Rare FMR1 gene mutations causing fragile $\mathrm{X}$ syndrome: a review. Am J Med Genet Part A. 2018;176(1):11-18. doi:10.1002/ajmg. a. 38504

6. Coffee B, Ikeda M, Budimirovic DB, Hjelm LN, Kaufmann WE, Warren ST. Mosaic FMR1 deletion causes fragile X syndrome and can lead to molecular misdiagnosis: a case report and review of the literature. Am J Med Genet Part A. 2008;146A(10):1358-1367. doi:10.1002/ajmg.a.32261

7. Tassanakijpanich N, Hagerman RJ, Worachotekamjorn J. Fragile $\mathrm{X}$ premutation and associated health conditions: a review. Clin Genet. 2021;99(6):751-760. doi:10.1111/cge.13924

8. Hagerman RJ, Berry-Kravis E, Hazlett HC, et al. Fragile X syndrome. Nat Rev Dis Prim. 2017. doi:10.1038/nrdp.2017.65

9. Taha MS, Haghighi F, Stefanski A, et al. Novel FMRP interaction networks linked to cellular stress. FEBS J. 2021;288(3):837-860. doi: $10.1111 /$ febs. 15443

10. Siomi H, Siomi MC, Nussbaum RL, Dreyfuss G. The protein product of the fragile X gene, FMR1, has characteristics of an RNA-binding protein. Cell. 1993;74(2):291-298. doi:10.1016/0092-8674(93)904 20-U

11. Ashley CT Jr, Wilkinson KD, Reines D, Warren ST. FMR1 protein contains conserved RNP-family domains and demonstrates selective RNA binding. Science (80-). 1993;262(5133):563-566. doi:10.1126/ science. 7692601

12. Bear MF, Huber KM, Warren ST. The mGluR theory of fragile $\mathrm{X}$ mental retardation. Trends Neurosci. 2004;27(7):370-377. doi:10.1016/j.tins.2004.04.009

13. Gatto CL, Broadie K. Genetic controls balancing excitatory and inhibitory synaptogenesis in neurodevelopmental disorder models. Front Synaptic Neurosci. 2010. doi:10.3389/fnsyn.2010.00004

14. Budimirovic DB, Haas-Givler B, Blitz R, et al. Consensus of the fragile $\mathrm{X}$ clinical and research consortium on clinical practices: autism Spectrum Disorder in Fragile X Syndrome. 2014;1-15.

15. Budimirovic DB, Subramanian M. Neurobiology of Autism and Intellectual Disability: fragile X Syndrome. 2 ed. In: Johnston M, Adams H, Fatemi A, editors. London: Oxford University Press;2016. doi:10.1093/med/9780199937837.001.0001

16. Saldarriaga W, Payán-Gómez C, González-Teshima LY, Rosa L, Tassone F, Hagerman RJ. Double genetic hit: fragile X syndrome and partial deletion of protein patched homolog 1 antisense as cause of severe autism spectrum disorder. J Dev Behav Pediatr. 2020;41 (9):724-728. doi:10.1097/DBP.0000000000000850

17. Sherman SL, Kidd SA, Riley C, et al. Forward: a registry and longitudinal clinical database to study fragile $\mathrm{X}$ syndrome. Pediatrics. 2017;139(Supplement 3):S183-S193. doi:10.1542/peds.2016-1159E

18. Loehr JP, Synhorst DP, Wolfe RR, Hagerman RJ. Aortic root dilatation and mitral valve prolapse in the fragile $\mathrm{X}$ syndrome. Am J Med Genet. 1986;23(1-2):189-194. doi:10.1002/ajmg.1320230113

19. Rahit KMTH, Tarailo-Graovac M. Genetic modifiers and rare mendelian disease. Genes (Basel). 2020;11(3):239. doi:10.3390/genes11030239

20. Li D, Yu J, Gu F, et al. The roles of two novel FBN1 gene mutations in the genotype-phenotype correlations of marfan syndrome and ectopia lentis patients with marfanoid habitus. Genet Test. 2008;12 (2):325-330. doi:10.1089/gte.2008.0002

21. Fahed AC, Wang M, Homburger JR, et al. Polygenic background modifies penetrance of monogenic variants for tier 1 genomic conditions. Nat Commun. 2020;11(1). doi:10.1038/s41467-020-17 374-3

22. Kim M, Costello J. DNA methylation: an epigenetic mark of cellular memory. Exp Mol Med. 2017;49(4):e322-e322. doi:10.1038/ emm.2017.10

23. Kraan CM, Baker EK, Arpone M, et al. Dna methylation at birth predicts intellectual functioning and autism features in children with fragile x syndrome. Int J Mol Sci. 2020;21(20):7735. doi:10.3390/ ijms 21207735 
24. Pieretti M, Zhang F, Fu YH, et al. Absence of expression of the FMR-1 gene in fragile X syndrome. Cell. 1991;66(4):817-822. doi:10.1016/0092-8674(91)90125-I

25. Nolin SL, Glicksman A, Houck GE, Brown WT, Dobkin CS. Mosaicism in fragile X affected males. Am J Med Genet. 1994;51 (4):509-512. doi:10.1002/ajmg.1320510444

26. Stöger R, Genereux DP, Hagerman RJ, Hagerman PJ, Tassone F, Laird CD. Testing the FMR1 promoter for mosaicism in dna methylation among cpg sites, strands, and cells in FMR1-expressing males with fragile x syndrome. PLoS One. 2011;6(8):e23648. doi:10.1371/ journal.pone.0023648

27. Pretto DI, Mendoza-Morales G, Lo J, et al. CGG allele size somatic mosaicism and methylation in FMR1 premutation alleles. $\mathrm{J} \mathrm{Med}$ Genet. 2014;51(5):309-318. doi:10.1136/jmedgenet-2013-102021

28. Jiraanont P, Kumar M, Tang H-T, et al. Size and methylation mosaicism in males with Fragile X syndrome. Expert Rev Mol Diagn. 2017;17(11):1023-1032. doi:10.1080/14737159.2017.1377612

29. Budimirovic DB, Schlageter A, Filipovic-Sadic S, et al. A genotype-phenotype study of high-resolution FMR1 nucleic acid and protein analyses in fragile $\mathrm{X}$ patients with neurobehavioral assessments. Brain Sci. 2020;10(10):694. doi:10.3390/brainsci10100694

30. Tassone F, Hagerman RJ, Loesch DZ, Lachiewicz A, Taylor AK, Hagerman PJ. Fragile X males with unmethylated, full mutation trinucleotide repeat expansions have elevated levels of FMR1 messenger RNA. Am J Med Genet. 2000;94(3):232-236. doi:10.1002/ 1096-8628(20000918)94:3<232::aid-ajmg9>3.0.CO;2-H

31. Dolskiy AA, Yarushkin AA, Grishchenko IV, et al. miRNA expression and interaction with the 3'UTR of FMR1 in FRAXopathy pathogenesis. Non-Coding RNA Res. 2021;6(1):1-7. doi:10.1016/j. ncrna.2020.11.006

32. Primerano B, Tassone F, Hagerman RJ, Hagerman P, Amaldi F, Bagni C. Reduced FMR1 mRNA translation efficiency in fragile $\mathrm{X}$ patients with premutations. RNA. 2002;8(12):1482-1488. doi:10.1017/S1355838202020642

33. Kaufmann WE, Abrams MT, Chen W, Reiss AL. Genotype, molecular phenotype, and cognitive phenotype: correlations in fragile $\mathrm{X}$ syndrome. Am J Med Genet. 1999. doi:10.1002/(SICI)1096-8628(19990402)83:4<286::aid-ajmg10>3.0.CO;2-H

34. Loesch DZ, Bui QM, Dissanayake C, et al. Molecular and cognitive predictors of the continuum of autistic behaviours in fragile $\mathrm{X}$. Neurosci Biobehav Rev. 2007. doi:10.1016/j.neubiorev.2006.09.007

35. Backes M, Genç B, Schreck J, Doerfler W, Lehmkuhl G, Von Gontard A. Cognitive and behavioral profile of fragile X boys: correlations to molecular data. Am J Med Genet. 2000;95(2):150-156. doi:10.1002/1096-8628(20001113)95:2<50::aid-ajmg11><50::aidajmg $11>3.0 . \mathrm{CO} ; 2-1$

36. Tassone F, Hagerman RJ, Iklé DN, et al. FMRP expression as a potential prognostic indicator in fragile $\mathrm{X}$ syndrome. Am J Med Genet. 1999;84(3):250-261. doi:10.1002/(SICI)1096-8628(19990 528) $84: 3<250:$ :aid-ajmg17>3.0.CO;2-4

37. Hall S, DeBernardis M, Reiss A. Social escape behaviors in children with fragile X syndrome. J Autism Dev Disord. 2006;36(7):935-947. doi:10.1007/s10803-006-0132-z

38. Bagni C, Zukin RS, Synaptic A. Perspective of Fragile X syndrome and autism spectrum disorders. Neuron. 2019. doi:10.1016/j. neuron.2019.02.041

39. Kim K, Hessl D, Randol JL, et al. Association between IQ and FMR1 protein (FMRP) across the spectrum of CGG repeat expansions. PLoS One. 2019;14(12):e0226811. doi:10.1371/journal.pone.0226811

40. Aliaga SM, Slater HR, Francis D, et al. Identification of males with cryptic fragile $\mathrm{x}$ alleles by methylation-Specific quantitative melt analysis. Clin Chem. 2016;62(2):343-352. doi:10.1373/clinchem.2015.244681

41. Baker EK, Arpone M, Aliaga SM, et al. Incomplete silencing of full mutation alleles in males with fragile $\mathrm{X}$ syndrome is associated with autistic features. Mol Autism. 2019;10(1). doi:10.1186/s13229-0190271-7
42. Baker EK, Arpone M, Vera SA, et al. Intellectual functioning and behavioural features associated with mosaicism in fragile $\mathrm{X}$ syndrome. $J$ Neurodev Disord. 2019;11(1). doi:10.1186/s11689-019-9288-7

43. Kraan CM, Godler DE, Amor DJ. Epigenetics of fragile X syndrome and fragile X-related disorders. Dev Med Child Neurol. 2019;61 (2):121-127. doi:10.1111/dmcn.13985

44. Rousseau F, Heitz D, Biancalana V, et al. Direct diagnosis by DNA analysis of the fragile X syndrome of mental retardation. Obstet Gynecol Surv. 1992;47(5):306-308. doi:10.1097/00006254-199205000-00008

45. Loesch DZ, Sherwell S, Kinsella G, et al. Fragile X-associated tremor/ataxia phenotype in a male carrier of unmethylated full mutation in the FMR1 gene. Clin Genet. 2012;82(1):88-92. doi:10.1111/ j.1399-0004.2011.01675.x

46. Santa María L, Pugin A, Alliende MA, et al. FXTAS in an unmethylated mosaic male with fragile X syndrome from Chile. Clin Genet. 2014;86(4):378-382. doi:10.1111/cge.12278

47. Baker EK, Arpone M, Kraan C, et al. FMR1 mRNA from full mutation alleles is associated with ABC-CFX scores in males with fragile $\mathrm{X}$ syndrome. Sci Rep. 2020;10(1). doi:10.1038/s41598-020-68465-6

48. Schneider A, Winarni TI, Cabal-Herrera AM, et al. Elevated FMR1mRNA and lowered FMRP - a double-hit mechanism for psychiatric features in men with FMR1 premutations. Transl Psychiatry. 2020;10 (1). doi:10.1038/s41398-020-00863-w

49. Dipple KM, McCabe ERB. Phenotypes of patients with "Simple" mendelian disorders are complex traits: thresholds, modifiers, and systems dynamics. Am J Hum Genet. 2000;66(6):1729-1735. doi: $10.1086 / 302938$

50. Schäffer AA. Digenic inheritance in medical genetics. J Med Genet. 2013;50(10):641-652. doi:10.1136/jmedgenet-2013-101713

51. Mineur YS, Sluyter F, De Wit S, Oostra BA, Crusio WE. Behavioral and neuroanatomical characterization of the Fmr1 knockout mouse. Hippocampus. 2002;12(1):39-46. doi:10.1002/hipo.10005

52. Bakker CE, Verheij C; The Dutch-Belgian Fragile X Consorthium, et al. Fmr1 knockout mice: a model to study fragile $\mathrm{X}$ mental retardation. Cell. 1994. doi:10.1016/0092-8674(94)90569-X

53. Errijgers V, Kooy RF. Genetic modifiers in mice: the example of the fragile X mouse model. Cytogenet Genome Res. 2004;105(24):448-454. doi:10.1159/000078218

54. Crawford H, Scerif G, Wilde L, et al. Genetic modifiers in rare disorders: the case of fragile $\mathrm{X}$ syndrome. Eur J Hum Genet. 2021;29(1):173-183. doi:10.1038/s41431-020-00711-x

55. Hessl D, Tassone F, Cordeiro L, et al. Brief report: aggression and stereotypic behavior in males with fragile X syndrome - Moderating secondary genes in a "single gene" disorder. J Autism Dev Disord. 2008;38(1):184-189. doi:10.1007/s10803-007-0365-5

56. Louhivuori V, Arvio M, Soronen P, Oksanen V, Paunio T, Castrén ML. The Val66Met polymorphism in the BDNF gene is associated with epilepsy in fragile $\mathrm{X}$ syndrome. Epilepsy Res. 2009;85(1):114-117. doi:10.1016/j.eplepsyres.2009.01.005

57. Stepniak B, Kästner A, Poggi G, et al. Accumulated common variants in the broader fragile $\mathrm{X}$ gene family modulate autistic phenotypes. EMBO Mol Med. 2015;7(12):1565-1579. doi:10.15252/emmm. 201505696

58. Tondo M, Poo P, Naudó M, et al. Predisposition to epilepsy in fragile $\mathrm{X}$ syndrome: does the Val66Met polymorphism in the BDNF gene play a role? Epilepsy Behav. 2011;22(3):581-583. doi:10.1016/j. yebeh.2011.08.003

59. Wassink TH, Hazlett HC, Davis LK, Reiss AL, Piven J. Testing for association of the monoamine oxidase a promoter polymorphism with brain structure volumes in both autism and the fragile $\mathrm{X}$ syndrome. $J$ Neurodev Disord. 2014;6(1). doi:10.1186/1866-1955-6-6

60. Chen ZY, Patel PD, Sant G, et al. Variant Brain-Derived Neurotrophic Factor (BDNF) (Met66) alters the intracellular trafficking and activity-dependent secretion of wild-type BDNF in neurosecretory cells and cortical neurons. $J$ Neurosci. 2004;24 (18):4401-4411. doi:10.1523/JNEUROSCI.0348-04.2004 
61. Szeszko PR, Lipsky R, Mentschel C, et al. Brain-derived neurotrophic factor val66met polymorphism and volume of the hippocampal formation. Mol Psychiatry. 2005;10(7):631-636. doi:10.1038/sj.mp.4001656

62. Chen ZY, Jing D, Bath KG, et al. Genetic variant BDNF (Val66Met) polymorphism alters anxiety-related behavior. Science (80-). 2006;314(5796):140-143. doi:10.1126/science.1129663

63. Gratacòs M, González JR, Mercader JM, de Cid R, Urretavizcaya M, Estivill X. Brain-derived neurotrophic factor Val66Met and psychiatric disorders: meta-analysis of case-control studies confirm association to substance-related disorders, eating disorders, and schizophrenia. Biol Psychiatry. 2007;61(7):911-922. doi:10.1016/j. biopsych.2006.08.025
64. AlOlaby RR, Sweha SR, Silva M, et al. Molecular biomarkers predictive of sertraline treatment response in young children with fragile X syndrome. Brain Dev. 2017;39(6):483-492. doi:10.1016/j. braindev.2017.01.012

65. Duy PQ, Budimirovic DB. Fragile X syndrome: lessons learned from the most translated neurodevelopmental disorder in clinical trials. Transl Neurosci. 2017;8(1). doi:10.1515/tnsci-2017-0002

\section{Publish your work in this journal}

The Application of Clinical Genetics is an international, peerreviewed open access journal that welcomes laboratory and clinical findings in the field of human genetics. Specific topics include: Population genetics; Functional genetics; Natural history of genetic disease; Management of genetic disease; Mechanisms of genetic disease;
Counselling and ethical issues; Animal models; Pharmacogenetics; Prenatal diagnosis; Dysmorphology. The manuscript management system is completely online and includes a very quick and fair peerreview system, which is all easy to use. Visit http://www.dovepress. com/testimonials.php to read real quotes from published authors. 